
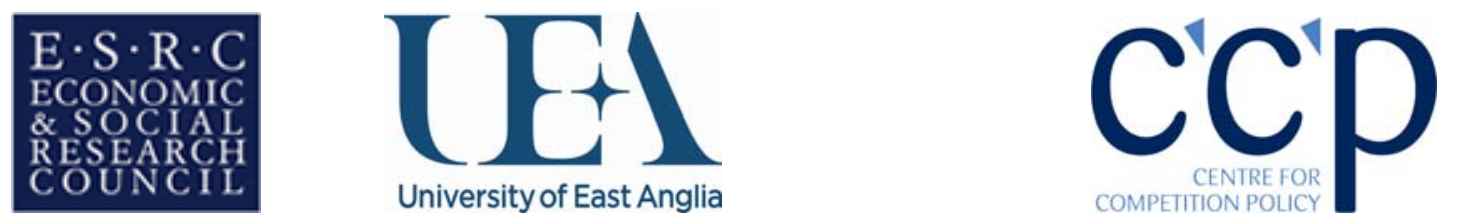

\title{
Price low and then price high or price high and then price low?
}

\author{
Stefania Sitzia \\ School of Economics and CBESS \\ University of East Anglia \\ Norwich, UK \\ s.sitzia@uea.ac.uk \\ Daniel John Zizzo \\ School of Economics, CBESS and CCP \\ University of East Anglia \\ Norwich, UK \\ d.zizzo@uea.ac.uk \\ CCP Working Paper 10-8
}

\begin{abstract}
:
The paper presents an experiment testing the hypothesis that, if consumers do not have well defined preferences and as a result their valuation of a new product is shaped by past experiences of prices, it may be more profitable for firms to follow a strategy of pricing high and then lower. We ran an individual choice experiment with a posted offer market setup, where different dynamic pricing strategies were implemented. We find evidence of preference shaping and the profitability of a 'high low' pricing strategy under a wide range of assumptions.

March 2010
\end{abstract}

JEL Classification Codes: C91, D03, D12, D21, L11.

Keywords: consumer market, dynamic price strategies, shaping effects, bounded rationality.

Acknowledgements: We thank Steve Davies, Andrea Isoni, Bruce Lyons, Bob Sugden and participants to presentations at the CBESS-CeDEX-CREED 
June 2009 conference and at ESRC Centre for Competition Policy, Free University of Berlin and University of Bath seminars for encouragement and advice, and Federica Alberti, James Watson and Kei Tsutsui for research assistance. ZTree was used to program the experimental software. The usual disclaimer applies. The support of the Economic and Social Research Council is gratefully acknowledged.

Contact Details: Daniel Zizzo - Corresponding author. Phone: +44-1603593668; Fax: +44-1603-456259. The experimental instructions can be found can be found online (http://www.uea.ac.uk/ ec601/). 


\section{Introduction}

Dan Ariely (2008) has noted how the Apple IPhone was originally priced at $\$ 600$, and, when it moved down to $\$ 200$, everyone thought it was a bargain to buy as a result. This paper devises an experiment trying to test this intuition: namely, that it may be profitable for companies to choose to price a new product high and then reduce the price, rather than provide a low introductory price and raise the price later. There are reasons why the latter has often been considered a good strategy by economists: in the presence of switching costs by at least a fraction of consumers, a low introductory price may be used to 'lock in' consumers and the price may be raised afterwards (e.g., Cabral, 2010); it may be used to signal low cost (Bagwell, 1987); it may be used to facilitate buyer experimentation when there is uncertainty about the product's quality (Schlee, 2001). We do not wish to deny that there are settings where a 'low price - high price' ('low high') strategy may be profitable. This paper, however, presents an experiment trying to test the opposite intuition: namely, that it may be profitable for firms first to price high and then low. Reasons why this might be the case, which have been identified in the industrial economics literature, include intertemporal price discrimination with durable goods (e.g., Conlisk et al., 1984), special parametrizations of switching costs models (Klemperer, 1995), and more cognate this paper - models of an introductory high price as a signal of quality under the assumption of heterogeneous (in part informed, in part uninformed) agents (Bagwell and Riordan, 1991). Our experiment has no durable goods, no (at least monetary) switching costs, and does not have the game theory structure that would justify Bagwell and Riordan equilibria.

We aim to show that a 'high price - low price' ('high low') strategy may nevertheless be profitable for companies because of shaping effects: shaping effects are changes in demand due to agents having unclear preferences and, as a result, their preferences being shaped by the decision environment (see Ariely et al., 2003, 2006; Loomes et al., 2003; Braga et al., 2009; Brooks et al., 2009; Tufano, 2010). If consumers have unclear preferences, their willingness to buy may be affected by anchors provided either artificially or through the operation of auction mechanisms. Specifically, having observed high prices implies a high reference price and a belief 
that a good deal is made when the price is decreased; conversely, having observed low prices implies a low reference price and a belief that a bad deal is made when the price is increased. We should, as a result, expect a positive relationship between past prices and current sales. There is an obvious connection between this idea and that of reference-dependent models of consumer behavior with endogenous reference points. ${ }^{1}$ This psychological mechanism is consistent with adaptation theory in marketing (Morris and Morris, 1990) and bears a close analogy with the success of the so called 'black hat/white hat' strategy in negotiation experiments: one can get better bargaining outcomes by starting tough and then softening up in the negotiation process than starting soft and then hardening up (Hilty and Carnevale, 1993). In spirit, it fits with the Bagwell and Riordan model insofar as a high price can indeed be here interpreted as a signal of high quality, even though the conditions of the Bagwell and Riordan model do not hold. Our behavioral mechanism may provide a powerful reason why 'high low' price strategies are observed, not only in the context of Ariely's (2008) mobile phones example but also, for example, in relation to appliances (Consumer Reports, 2008), video consoles (e.g., Fitzgerald, 1992), or color television sets (Krishnan et al., 1999). It reflects the admonition by marketers that price discounts may undermine the perceived economic value of a good (Lucke and Hogan, 2007). ${ }^{2}$

The advantage of the experimental methodology is that we are able to identify the relevance of shaping effects for the profitability of a high low strategy while controlling for alternative explanations or, indeed, for additional reasons that may impact on real world price competition, such as the toughness of market competition. Our experiment is the first that tries to systematically test the profitability of a shaping effect related 'high low' strategy in an experimental retail market. It is most closely

\footnotetext{
${ }^{1}$ Munro and Sugden (2003) and Köszegi and Rabin (2006) are two examples of such theories; Heidhues and Köszegi (2008) contains an application to a price competition setting. Isoni (2009) contains a recent formalization of the idea of 'bad deal aversion,' which he employs to explain the willingness to pay - willingness to accept disparity observed in contingent valuation studies: subjects will demand more if they feel they are having a good deal relative to the expected price and less if they feel they are having a bad deal relative to the expected price. Note that, although we talk here of 'high low' and 'low high', one could more precisely identify these strategies as price high and then lower vs. price low and then higher. We use the 'high low' and 'low high' terminology here simply as less cumbersome.

2 There is a technical literature in marketing science that looks at optimal pricing strategies based on decreasing prices (e.g., Bass, 1980; Krishnan et al., 1999). This research, however, takes the empirical sales curve in time as a given rather than attempting to explain it as a function of price-dependent consumer preferences (or the kind of informational issues highlighted in Bagwell and Riordan, 1991).
} 
related to the experimental work by Sitzia and Zizzo (2009), who found - in experimental retail markets akin to those of this paper - evidence from regression analysis that demand seemed to depend on past prices, and, namely, that demand at time $t$ was higher if the price at time $t-1$ was higher. The purpose of that experiment was not however to test shaping effects in general, nor to test the profitability of a strategy trying to exploit such shaping effects.

As in Sitzia and Zizzo (2009), we used lotteries of different degrees of complexity as products that consumers could buy. The choice of lotteries as products was not only for comparability to Sitzia and Zizzo, but also and more significantly to ensure the novelty of the product for all subjects, to ensure that it was a product that subjects could buy over a number of rounds without quickly and heterogeneously getting tired of it, and so ultimately to maximize experimental control. Experiments on reference dependent preferences have shown that similar behavioral features to those found with lotteries are found with real commodities (compare, e.g., Bateman et al., 1997, with Kahneman and Tversky, 1979), and this, together with the danger of loss of control from other product choices (e.g., due to satiation), implies the usefulness of our choice. Another reason for having lottery products is the simple way we can control for level of complexity and therefore potential product value uncertainty using a lottery paradigm: we indexed complexity using the same procedure as in Sitzia and Zizzo (2009), which in turns relies on Sonsino et al. (2001); research still needs to be conducted on how to index complexity with real commodities. Of course, lottery tickets are a real commodity by themselves and one that is in high demand in the real world. ${ }^{3}$

Our key finding is that shaping effects do matter, and that a high low strategy would indeed be profitable for firms under different assumptions about cost and volume of demand. This is true no matter the type of product employed. The rest of this paper is structured as follows. Section 2 presents the experimental design, section 3 presents the results and section 4 concludes.

\footnotetext{
${ }^{3}$ For example, in the 2008/09 financial year the U.K. National Lottery sold $£ 5.15$ billions in lottery tickets, up from £ 4.96 billions in 2007/08 (source: Camelot Stakeholder Report, 2009, p. 2).
} 


\section{Experimental Design}

\subsection{General Outline}

We ran the experiment at our university during the spring term 2009. It consisted of repeated opportunities to purchase good in a posted offer market setup with only one product involved. ${ }^{4}$ Before beginning the task, subjects completed a questionnaire to check their understanding and had an opportunity to ask questions of clarification. After the experimenters answered any question of clarification and subjects did two practice periods with an example product (see Table 1) the posted offer market task started. It involved two phases, phase 1 and phase 2, of 10 independent trading periods each.

The products were either a lottery used in Sonsino et al. (2002), which we label as S3, or one of two lotteries used in Sitzia and Zizzo (2009), which we label as S1 and S2, albeit scaled up to have the same expected value as that in Sonsino et al.; furthermore, two more complex versions of each product were devised, based on the procedure described in Sonsino et al. and in Sitzia and Zizzo, a procedure which is based on mixing the lotteries with themselves (see Appendix $A$ ). The products are presented in Table 1, and all had an expected value of 107 experimental points. The lotteries were played out at the end of the experiment based on a single random draw applicable for all units of the lottery bought during the experiment; subjects received no feedback on the lottery outcome during the experiment. Points were converted at the end of the experiment at the rate of 975 experimental points to a British pound.

\footnotetext{
${ }^{4}$ It was preceded by a lottery choice task, which is not the object of this paper and was constant across treatments.
} 
Table 1: Products Employed in Experiment

\begin{tabular}{|c|c|c|c|c|c|c|c|c|}
\hline \multicolumn{3}{|l|}{ Product S1 } & \multicolumn{3}{|l|}{ Product S2 } & \multicolumn{3}{|l|}{ Product S3 } \\
\hline Outcomes & Probabilities & Results & Outcomes & Probabilities & Results & Outcomes & Probabilities & Results \\
\hline 1 & $20.00 \%$ & 112 & 1 & $50.00 \%$ & 198 & 1 & $30.00 \%$ & 150 \\
\hline 2 & $50.00 \%$ & 57 & 2 & $20.00 \%$ & 50 & 2 & $40.00 \%$ & 80 \\
\hline 3 & $30.00 \%$ & 187 & 3 & $30.00 \%$ & 113 & 3 & $30.00 \%$ & 100 \\
\hline \multicolumn{3}{|l|}{ Product $\mathrm{C} 1$} & \multicolumn{3}{|l|}{$\overline{\text { Product C2 }}$} & \multicolumn{3}{|l|}{ Product C3 } \\
\hline Outcomes & Probabilities & Results & Outcomes & Probabilities & Results & Outcomes & Probabilities & Results \\
\hline 1 & $20.00 \%$ & 84.5 & 1 & $12.00 \%$ & 155.5 & 1 & $24.00 \%$ & 115 \\
\hline 2 & $9.00 \%$ & 187 & 2 & $30.00 \%$ & 124 & 2 & $9.00 \%$ & 150 \\
\hline 3 & $12.00 \%$ & 149.5 & 3 & $4.00 \%$ & 113 & 3 & $16.00 \%$ & 80 \\
\hline 4 & $4.00 \%$ & 112 & 4 & $9.00 \%$ & 198 & 4 & $9.00 \%$ & 100 \\
\hline 5 & $30.00 \%$ & 122 & 5 & $25.00 \%$ & 50 & 5 & $24.00 \%$ & 90 \\
\hline 6 & $25.00 \%$ & 57 & 6 & $20.00 \%$ & 81.5 & 6 & $18.00 \%$ & 125 \\
\hline \multicolumn{3}{|c|}{ Product VC1 } & \multicolumn{3}{|c|}{ Product VC2 } & \multicolumn{3}{|c|}{ Product VC3 } \\
\hline Outcomes & Probabilities & Results & Outcomes & Probabilities & Results & Outcomes & Probabilities & Results \\
\hline 1 & $7.50 \%$ & 1 & 1 & $3.00 \%$ & 58.85 & 1 & $2.70 \%$ & 104 \\
\hline 2 & $3.00 \%$ & 110.4 & 2 & $2.70 \%$ & 198 & 2 & $2.70 \%$ & 146.5 \\
\hline 3 & $12.50 \%$ & 57 & 3 & $4.50 \%$ & 187.64 & 3 & $2.70 \%$ & 146 \\
\hline 4 & $2.70 \%$ & 187 & 4 & $7.50 \%$ & 54.44 & 4 & $2.70 \%$ & 103.5 \\
\hline 5 & $7.50 \%$ & 66.1 & 5 & $2.00 \%$ & 111.11 & 5 & $4.80 \%$ & 139.5 \\
\hline 6 & $2.00 \%$ & 108.15 & 6 & $1.20 \%$ & 118.95 & 6 & $2.70 \%$ & 107.5 \\
\hline 7 & $1.80 \%$ & 184.75 & 7 & $3.00 \%$ & 111.14 & 7 & $3.60 \%$ & 144.4 \\
\hline 8 & $3.00 \%$ & 177.85 & 8 & $3.00 \%$ & 62.25 & 8 & $4.80 \%$ & 84.9 \\
\hline 9 & $2.00 \%$ & 62.5 & 9 & $3.00 \%$ & 185.09 & 9 & $2.70 \%$ & 100 \\
\hline 10 & $4.50 \%$ & 183.1 & 10 & $12.50 \%$ & 50 & 10 & $4.80 \%$ & 85.6 \\
\hline 11 & $1.80 \%$ & 119.5 & 11 & $1.20 \%$ & 115.55 & 11 & $3.60 \%$ & 98.4 \\
\hline 12 & $3.00 \%$ & 175.65 & 12 & $1.80 \%$ & 195.45 & 12 & $3.60 \%$ & 101.9 \\
\hline 13 & $5.00 \%$ & 58.65 & 13 & $5.00 \%$ & 54.41 & 13 & $6.40 \%$ & 80 \\
\hline 14 & $5.00 \%$ & 106.5 & 14 & $1.80 \%$ & 121.5 & 14 & $3.60 \%$ & 87 \\
\hline 15 & $7.50 \%$ & 174 & 15 & $4.50 \%$ & 64.8 & 15 & $3.60 \%$ & 98.6 \\
\hline 16 & $4.50 \%$ & 177.9 & 16 & $7.50 \%$ & 60.36 & 16 & $4.80 \%$ & 81.6 \\
\hline 17 & $1.80 \%$ & 181.75 & 17 & $7.50 \%$ & 183.2 & 17 & $3.60 \%$ & 141.1 \\
\hline 18 & $1.20 \%$ & 117.25 & 18 & $0.80 \%$ & 113 & 18 & $3.60 \%$ & 90.5 \\
\hline 19 & $1.20 \%$ & 114.25 & 19 & $2.00 \%$ & 108.59 & 19 & $3.60 \%$ & 140.9 \\
\hline 20 & $1.20 \%$ & 179.5 & 20 & $4.50 \%$ & 193.56 & 20 & $3.60 \%$ & 145.1 \\
\hline 21 & $0.80 \%$ & 112 & 21 & $2.00 \%$ & 56.3 & 21 & $3.60 \%$ & 86.5 \\
\hline 22 & $4.50 \%$ & 70 & 22 & $1.20 \%$ & 189.5 & 22 & $2.70 \%$ & 150 \\
\hline 23 & $2.00 \%$ & 110.35 & 23 & $3.00 \%$ & 117.06 & 23 & $3.60 \%$ & 83 \\
\hline 24 & $3.00 \%$ & 64.75 & 24 & $1.80 \%$ & 192.05 & 24 & $4.80 \%$ & 81.4 \\
\hline 25 & $3.00 \%$ & 115.6 & 25 & $5.00 \%$ & 51.89 & 25 & $3.60 \%$ & 102.6 \\
\hline 26 & $5.00 \%$ & 60.85 & 26 & $5.00 \%$ & 106.7 & 26 & $2.70 \%$ & 142.5 \\
\hline 27 & $3.00 \%$ & 67.75 & 27 & $3.00 \%$ & 187.61 & 27 & $4.80 \%$ & 97 \\
\hline
\end{tabular}

Notes: The products were nine lotteries with between 3 and 27 outcomes, each occurring with a given probability and entailing a different result in terms of experimental points for buyers.

It is not in any way relevant for the scope of this paper to believe that products of different levels of complexity differ only in terms of complexity; it is difficult to argue against the claim that perceived riskiness may have changed as well, at least in relation to some products (see Appendix A for details). The key message is simply 
that, depending on the experimental treatment, we used at least three of these products, or all nine of them, to verify the robustness of our results, as detailed below.

\subsection{The Posted Offer Market Task}

Each trading period subjects were endowed with 650 experimental points. Their task was each period to decide whether and how much they wanted to buy of a product on sale at a randomly chosen price. The product did not change throughout the experiment and was one of the products presented in Table 1.

In each period a price was chosen randomly from a uniform price distribution within a range. We label the price distributions as Very Low (ranging between 57 and 77), Low (87 - 107), Medium (117 - 137), High (147 - 167) and Very High (177-197). In all experimental treatments, the second group of 10 periods (phase 2) was run with prices drawn from the Medium distribution; the treatments differed, however, in the price distributions used in the first 10 periods (phase 1).

We began the experiment by running treatments 1, 2 and 3. Each of these treatments was run with 108 subjects per product sold, and all 9 products were used with different subjects, so a total of 324 subjects participated to these treatments. Treatment 2 was our control treatment: prices were drawn from the Medium distribution throughout the experiment, including phase 1. Treatment 1 drew phase 1 prices from the Low distribution; Treatment 3 drew them from the High distribution. Treatment 1 implemented a 'low-high' strategy where prices begin low (phase 1) and they then increase (phase 2); conversely, treatment 3 implemented a 'high-low' strategy where prices begin high and then decrease.

As we found our results (described in section 3 ) to be insensitive to the level of product complexity, and we had an opportunity to run a small number of additional sessions, we ran an additional two treatments, 0 and 4, with three products (namely S1, S2 and S3), to test further the effectiveness of different dynamic strategies on sales and profits. An additional 60 subjects participated to these treatments. Treatment 0 drew prices from the Very Low distribution in periods 1-5 and from the Low distribution in periods 6-10; Treatment 4 drew prices from the Very High distribution in periods 1-5 and from the High distribution in periods 6-10. Overall, the 
average price in phase 1 increases as we move from treatment 0 to $1,2,3$ and 4 , with treatment 0 also implementing a low and rising price strategy and treatment $4 \mathrm{a}$ high and decreasing price strategy. A summary of the experimental treatments is provided in Table 2.

Table 2: Experimental Treatments

\begin{tabular}{|c|c|c|c|c|c|}
\hline \multirow{2}{*}{$\begin{array}{c}\text { Price } \\
\text { Distribution }\end{array}$} & \multirow{2}{*}{$\begin{array}{l}\text { Price } \\
\text { Range }\end{array}$} & \multirow[b]{2}{*}{ Treatment } & \multicolumn{3}{|c|}{ Periods } \\
\hline & & & $1-5$ & $6-10$ & $11-20$ \\
\hline Very Low (VL) & $57-77$ & 0 & $\mathrm{VL}$ & $\mathrm{L}$ & M \\
\hline Low (L) & $87-107$ & 1 & $\mathrm{~L}$ & $\mathrm{~L}$ & M \\
\hline Medium (M) & $117-137$ & 2 & M & M & M \\
\hline $\operatorname{High}(\mathrm{H})$ & $147-167$ & 3 & $\mathrm{H}$ & $\mathrm{H}$ & M \\
\hline Very High (VH) & $177-197$ & 4 & $\mathrm{VH}$ & $\mathrm{H}$ & $\mathrm{M}$ \\
\hline
\end{tabular}

Notes: Phase 1 was in periods 1-10; phase 2 was in periods 11-20.

\section{$2.3 \quad$ Earnings}

The earnings were the points accumulated in the experiment. The product on sale in the posted offer market tasks was played out at the end of the experiment to determine its value, and then multiplied by the number of units bought throughout the experiment. The unspent endowment accumulated throughout the 20 periods was also part of the earnings. Earnings in points were converted into pounds and paid to the subjects. Average payments were 15.84 British pounds.

\section{Experimental Results}

\subsection{Sales and Expenditure}

Figure 1 and Table 3 report the quantities bought in phase 1 and phase 2 for each treatment. 
Table 3: Average Sales by Treatment, Phase and Product

\begin{tabular}{|c|c|c|c|c|c|c|c|c|c|}
\hline \multirow[b]{2}{*}{ Product } & \multicolumn{3}{|c|}{ Treatment 1} & \multicolumn{3}{|c|}{ Treatment 2} & \multicolumn{3}{|c|}{ Treatment 3} \\
\hline & Phase 1 & Phase 2 & Overall & Phase 1 & Phase 2 & Overall & Phase 1 & Phase 2 & Overall \\
\hline S1 & 2.80 & 1.17 & 1.98 & 1.83 & 1.70 & 1.76 & 1.03 & 2.08 & 1.55 \\
\hline S2 & 2.45 & 0.97 & 1.71 & 1.52 & 1.44 & 1.48 & 0.97 & 1.85 & 1.41 \\
\hline S3 & 1.73 & 0.77 & 1.25 & 1.26 & 1.43 & 1.34 & 1.16 & 1.72 & 1.44 \\
\hline $\mathrm{C} 1$ & 2.43 & 1.08 & 1.76 & 1.92 & 1.98 & 1.95 & 1.10 & 1.84 & 1.47 \\
\hline $\mathrm{C} 2$ & 3.08 & 1.27 & 2.17 & 1.28 & 1.04 & 1.16 & 2.08 & 2.68 & 2.38 \\
\hline C3 & 3.48 & 1.01 & 2.25 & 1.22 & 1.03 & 1.13 & 0.91 & 1.61 & 1.26 \\
\hline VC1 & 1.58 & 0.60 & 1.09 & 1.19 & 0.91 & 1.05 & 1.35 & 2.03 & 1.69 \\
\hline $\mathrm{VC} 2$ & 2.30 & 1.49 & 1.90 & 1.78 & 1.94 & 1.86 & 1.28 & 1.66 & 1.47 \\
\hline VC3 & 2.99 & 1.08 & 2.04 & 1.63 & 1.59 & 1.61 & 1.41 & 2.29 & 1.85 \\
\hline Type 1 & 2.27 & 0.95 & 1.61 & 1.64 & 1.53 & 1.59 & 1.16 & 1.99 & 1.57 \\
\hline Type 2 & 2.61 & 1.24 & 1.93 & 1.53 & 1.48 & 1.50 & 1.44 & 2.06 & 1.75 \\
\hline Type 3 & 2.73 & 0.95 & 1.84 & 1.37 & 1.35 & 1.36 & 1.16 & 1.87 & 1.52 \\
\hline Simple & 2.33 & 0.97 & 1.65 & 1.53 & 1.52 & 1.53 & 1.05 & 1.88 & 1.47 \\
\hline Complex & 3.00 & 1.12 & 2.06 & 1.47 & 1.35 & 1.41 & 1.36 & 2.04 & 1.70 \\
\hline V. Complex & 2.29 & 1.06 & 1.68 & 1.54 & 1.48 & 1.51 & 1.35 & 1.99 & 1.67 \\
\hline Overall & 2.54 & 1.05 & 1.79 & 1.51 & 1.45 & 1.48 & 1.25 & 1.97 & 1.61 \\
\hline & & reatment & & & reatmen & & & & \\
\hline Product & Phase 1 & Phase 2 & Overall & Phase 1 & Phase 2 & Overall & & & \\
\hline S1 & 3.85 & 1.05 & 2.45 & 0.72 & 0.86 & 0.79 & & & \\
\hline S2 & 3.07 & 1.32 & 2.20 & 1.13 & 2.12 & 1.63 & & & \\
\hline $\mathrm{S} 3$ & 3.28 & 1.06 & 2.17 & 1.43 & 2.17 & 1.80 & & & \\
\hline Overall & 3.40 & 1.14 & 2.27 & 1.09 & 1.72 & 1.41 & & & \\
\hline
\end{tabular}


Notes: Type 1, 2 and 3 average sales are the average of S1, C1 and VC1 sales; S2, C2 and VC2 sales; and S3, C3 and VC3 sales, respectively. Simple, Complex and V. Complex average sales are the average of S1, S2 and S3 sales; C1, C2 and C3 sales; and VC1, VC2 and VC3 sales, respectively.

Figure 1: Mean Sales by Phase and Treatment

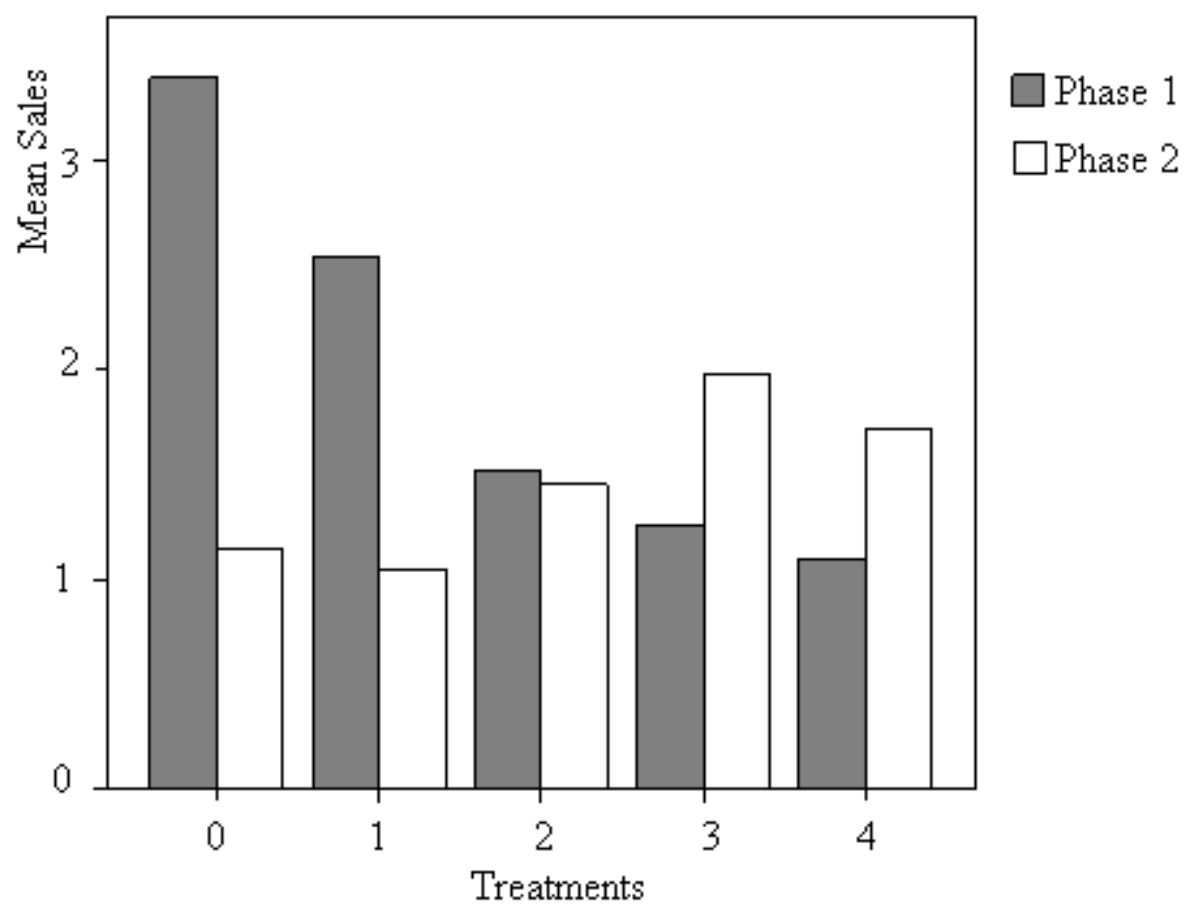

Phase 1 average prices increased as we move from treatment 0 to 4 and, unsurprisingly, this is borne out in declining sales. In the absence of shaping effects, it is not obvious however that we should observe significantly differences in the quantity bought in phase 2 , since the pricing strategy is the same across treatments in this phases and so prices were on average the same. ${ }^{5}$ Conversely, the shaping effects prediction is that in treatments 3 and 4 we should observe greater sales than in the other treatments, and especially treatments 0 and 1. Table 3 and Figure 1 show that sales were higher in treatments 3 and 4 than in the other treatments, with treatment 3 phase 2 sales being around 80 per cent greater than those in treatment 0 and 1. Treatment 3 sales were significantly greater than those in treatments 0,1 and 2 (Mann Whitney $p<0.01$ ); the shaping effect prediction of greater sales in treatment 4 than in treatment 0 and 1 is also supported (Mann Whitney $p<0.05$ ), though not for

\footnotetext{
${ }^{5}$ There may be income and portfolio effects leading to different outcomes in phase 2. These are discussed and controlled for in the regression analysis of section 2.3. We also checked, and were able to confirm, that the prices chosen randomly by the computer were indeed on average the same across treatments.
} 
treatment 2. We also performed a Kruskal-Wallis test whose result shows that the differences in units bought in phase 2 across treatments are globally statistically significant $(p<0.001)$. Therefore, it appears that altering phase 1 prices produced a change in phase 2 sales which was consistent with shaping effects, as more sales occurred with a 'high and reducing' pricing strategy than with a 'low and increasing' pricing strategy or the control treatment, particularly in the case of treatment 3.

Treatment 3 seems the most effective strategy. When we move from treatment 1 (with a Very Low - Low - Medium price sequence) to 2 (with a Low - Medium price sequence) and from treatment 4 (with a Very Low - Low - Medium price sequence) to 5 (with a price sequence Low - Medium) the number of units bought did not change significantly. Gradual adjustment of prices from extremely high or low levels seems not to make much of a difference.

Result 1: The number of units bought is significantly greater with the 'price high and then lower' strategies of treatments 3 and 4 than with the 'price low and then higher' strategies of treatments 0 and 1 ; the number of units bought in treatment 3 is also greater than in the baseline treatment 2 . This is consistent with shaping effects.

Higher sales do not necessarily mean higher expenditure and thus higher revenue for firms, of course. For example, high sales with a low price may imply lower revenue for firms than low sales with a high price. Table 4 shows the average expenditure broken down by phase. 
Table 4: Average Expenditures by Treatment, Phase and Product

\begin{tabular}{|c|c|c|c|c|c|c|c|c|c|}
\hline \multirow[b]{2}{*}{ Product } & \multicolumn{3}{|c|}{ Treatment 1} & \multicolumn{3}{|c|}{ Treatment 2} & \multicolumn{3}{|c|}{ Treatment 3} \\
\hline & Phase 1 & Phase 2 & Overall & Phase 1 & Phase 2 & Overall & Phase 1 & Phase 2 & Overall \\
\hline S1 & 267.65 & 147.66 & 207.65 & 232.68 & 212.35 & 222.52 & 160.54 & 261.78 & 211.16 \\
\hline S2 & 236.27 & 121.61 & 178.94 & 190.65 & 182.10 & 186.38 & 149.64 & 233.74 & 191.69 \\
\hline S3 & 163.26 & 96.23 & 129.75 & 159.58 & 178.17 & 168.88 & 180.58 & 215.98 & 198.28 \\
\hline $\mathrm{C} 1$ & 231.86 & 137.05 & 184.45 & 242.19 & 248.63 & 245.41 & 172.84 & 232.78 & 202.81 \\
\hline $\mathrm{C} 2$ & 293.13 & 158.35 & 225.74 & 160.11 & 129.70 & 144.90 & 322.40 & 338.15 & 330.28 \\
\hline C3 & 332.39 & 128.68 & 230 & .71 & 129.60 & 15 & 2.40 & .74 & 172.35 \\
\hline VC1 & 150.87 & 75.93 & 113.40 & 148.97 & 112.74 & 130.85 & 210.91 & 258.54 & 234.73 \\
\hline $\mathrm{VC} 2$ & 219.02 & 188.33 & 203.67 & 225.41 & 243.14 & 234.28 & 200.42 & 207.55 & 203.98 \\
\hline $\mathrm{VC} 3$ & 287.30 & 136.37 & 211.83 & 206.76 & 201.36 & .06 & 220.94 & 289.69 & 255.32 \\
\hline Type 1 & 216.79 & 120.21 & 168.50 & 207.95 & 191.24 & 199.59 & 181.43 & 251.03 & 216.23 \\
\hline Type 2 & 249.47 & 156.09 & 202.78 & 192.06 & 184.98 & 188.52 & 224.15 & 259.81 & 241.98 \\
\hline Type 3 & 260.98 & 120.43 & 190.70 & 173.68 & 169.71 & 171.70 & 180.83 & 236.47 & 208.65 \\
\hline Simple & 222.39 & 121.83 & & 31 & 190.87 & & 163.59 & .16 & 0.38 \\
\hline Complex & 285.79 & 141.36 & 213.58 & 185.67 & 169.31 & 177.49 & 212.06 & 258.23 & 235.14 \\
\hline V. Complex & 219.06 & 133.54 & 176.30 & 193.71 & 185.75 & 189.73 & 210.76 & 251.93 & 231.34 \\
\hline Overall & 242.41 & 132.24 & 187.33 & 191.23 & 181.98 & 186.60 & 195.47 & 249.11 & 222.29 \\
\hline \multicolumn{4}{|c|}{ Treatment 0} & \multicolumn{3}{|c|}{ Treatment 4} & & & \\
\hline Product & Phase 1 & Phase 2 & Overall & Phase 1 & Phase 2 & Overall & & & \\
\hline S1 & 288.69 & 132.26 & 210.48 & 123.75 & 106.62 & 115.19 & & & \\
\hline S2 & 231.47 & 167.99 & 199.73 & 188.02 & 265.20 & 226.61 & & & \\
\hline S3 & 243.98 & 132.33 & 188.16 & 245.46 & 274.19 & 259.83 & & & \\
\hline Overall & 254.71 & 144.19 & 199.45 & 185.74 & 215.34 & 200.54 & & & \\
\hline
\end{tabular}


Notes: Type 1, 2 and 3 average expenditures are the average of S1, C1 and VC1 expenditures; S2, C2 and VC2 expenditures; and S3, C3 and VC3 expenditures, respectively. Simple, Complex and V. Complex average expenditures are the average of S1, S2 and S3 sales; C1, C2 and C3 expenditures; and VC1, VC2 and VC3 expenditures, respectively.

Figure 2: Mean Expenditures by Phase and Treatment

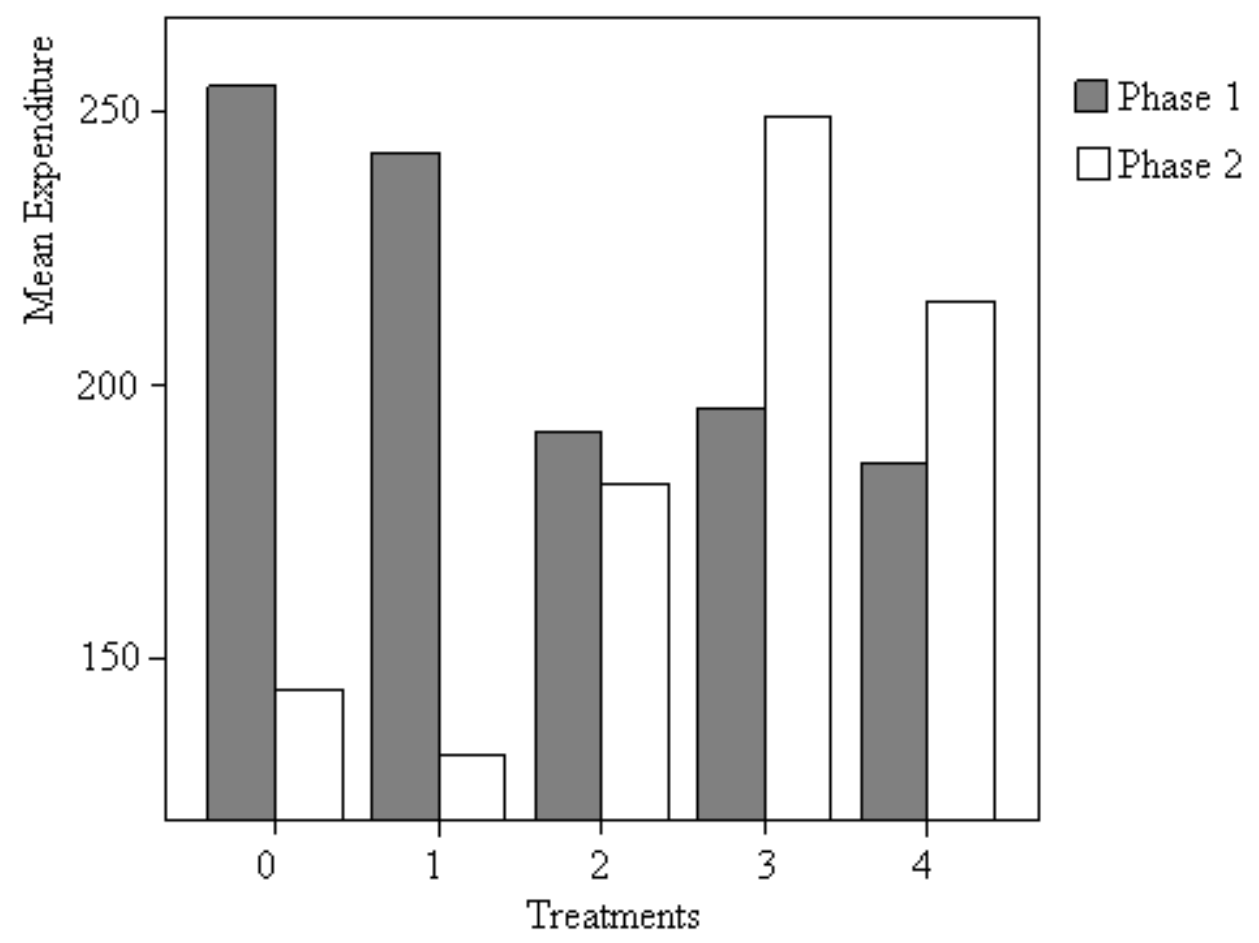

In phase 1 the expenditure decreases as we move from treatment 0 and 1 to the others, reflecting the price elasticity of demand for given average price levels across treatments. In phase 2 the expenditure is lower in treatment 0 and 1 than in 2 , 3 and 4 . The shaping effect prediction that expenditure is greater in treatment 3 is supported in relation to treatments 0 ( $p<0.001), 1(p<0.001)$ and $2(p=0.01)$; the same prediction in relation to treatment 4 receives support in relation to treatment 0 $(p<0.06)$ and $1(p<0.05)$. Table 4 confirms that, even though prices are on average the same, phase 2 expenditure is greater by around 50 per cent or more in treatments 3 and 4 than in treatments 4 , and, as before, the treatment 3 strategy seems the most effective. A Kruskal-Wallis test confirms that the differences among treatments in phase 2 are globally statistically significant $(p<0.001)$.

Result 2: Consistently with shaping effects, expenditure in phase 2 is significantly greater in treatments 3 and 4 than in treatments 0 and 1 . 
Tables 3 and 4 broadly show the same pattern of results for different products. This is confirmed in statistical tests checking, e.g., for whether product complexity had any impact on sales and profitability. We found no evidence that it did.

Result 3: Product complexity did not affect sales and expenditure.

\subsection{Regression analysis}

While the analysis of the previous section is useful, it does not control for a number of other factors such as period by period dynamics in prices and sales, learning, and the current asset portfolio held by each consumer, which may be relevant for our key conclusion that phase 2 appears characterized by shaping effects. We do so through the random effects regression analysis considered in this sub-section, and which controls for subject level non independence of observations. ${ }^{6}$

The dependent variable is the quantity bought and the regressors are the price, the lagged price, the type of product and the level of product complexity (as detailed below), the lagged income, the lagged total sales, the market period (MarketPeriod) and dummies for the treatments. In addition, there are several interaction variables to capture slope effects.

\footnotetext{
${ }^{6}$ Random effects are considered appropriate relative to simply correcting standard errors when the number of cross-sectional units is large relative to the number of repeated observations, as is the case in our dataset (Kennedy, 1998). That being said, alternative specifications employing error clustering are contained in Appendix $\mathrm{B}$ and broadly yield the same results.
} 
Table 5: Random effects Regressions on Sales and Expenditures

\begin{tabular}{|c|c|c|c|c|c|c|}
\hline \multirow[b]{2}{*}{ Variables } & \multicolumn{3}{|c|}{ Regression on Sales } & \multicolumn{3}{|c|}{ Regression on Expenditure } \\
\hline & $\beta$ & S.E. & $P$ & $\beta$ & S.E. & $P$ \\
\hline$\overline{\text { Price }}$ & -0.070 & 0.009 & 0.000 & -7.531 & 1.134 & 0.000 \\
\hline Lagged Price & 0.007 & 0.002 & 0.000 & 0.942 & 0.231 & 0.000 \\
\hline Products 1 & -0.007 & 0.082 & 0.933 & -0.810 & 10.298 & 0.937 \\
\hline Products2 & 0.066 & 0.082 & 0.418 & 8.466 & 10.313 & 0.412 \\
\hline Complexity & 0.248 & 0.477 & 0.603 & 23.374 & 59.862 & 0.696 \\
\hline Complexity*Price & -0.002 & 0.004 & 0.590 & -0.191 & 0.469 & 0.683 \\
\hline Lagged Income & -0.0008 & 0.000 & 0.000 & -0.096 & 0.010 & 0.000 \\
\hline Lagged Total Sales & 0.032 & 0.002 & 0.000 & 4.106 & 0.262 & 0.000 \\
\hline MarketPeriod & 0.439 & 0.054 & 0.000 & 55.120 & 6.850 & 0.000 \\
\hline T0 & -0.181 & 0.399 & 0.650 & -17.415 & 50.117 & 0.728 \\
\hline $\mathrm{T} 1$ & -0.829 & 0.255 & 0.001 & -101.227 & 32.114 & 0.002 \\
\hline $\mathrm{T} 3$ & 1.081 & 0.250 & 0.000 & 141.831 & 31.357 & 0.000 \\
\hline $\mathrm{T} 4$ & 0.121 & 0.376 & 0.747 & 22.855 & 47.262 & 0.629 \\
\hline MarketPeriod*T0 & 0.024 & 0.022 & 0.279 & 2.731 & 2.795 & 0.329 \\
\hline MarketPeriod*T1 & 0.041 & 0.015 & 0.005 & 5.054 & 1.864 & 0.007 \\
\hline MarketPeriod*T3 & -0.056 & 0.015 & 0.000 & -7.372 & 1.870 & 0.000 \\
\hline MarketPeriod*T4 & -0.011 & 0.022 & 0.616 & -1.811 & 2.800 & 0.518 \\
\hline cPrice*T0 & 0.042 & 0.012 & 0.001 & 5.032 & 1.550 & 0.001 \\
\hline cPrice*T1 & 0.051 & 0.007 & 0.000 & 6.048 & 0.933 & 0.000 \\
\hline cPrice*T3 & 0.017 & 0.007 & 0.021 & 2.625 & 0.928 & 0.005 \\
\hline cPrice*T4 & 0.023 & 0.012 & 0.053 & 3.288 & 1.515 & 0.030 \\
\hline Constant & 8.859 & 1.186 & 0.000 & 945.455 & 148.938 & 0.000 \\
\hline
\end{tabular}

We expect the number of units bought to depend negatively on the price. The lagged price shows whether the number of units bought depends on the past price: Sitzia and Zizzo (2009) found that sales were positively dependent on past prices, and interpreted this as period by period evidence for shaping effects. Products1 is a dummy whose value is 1 when the products are S1, C1 and VC1 and zero otherwise. Products2 is 1 when the products are S2, C2 and VC2 and zero otherwise. Complexity is 0 when the product is simple $(\mathrm{S} 1, \mathrm{~S} 2, \mathrm{~S} 3), 1$ when the product is complex $(\mathrm{C} 1, \mathrm{C} 2, \mathrm{C} 3)$ and 2 when the product is very complex (VC1, VC2, VC3). ${ }^{7}$ The lagged income is the number of experimental points that each subject has earned so far in the experiment. The income is computed as the endowment saved plus the number of units bought times the expected value of each unit (that is, 107). It is not their actual income, since the return of the product they have bought will be

\footnotetext{
${ }^{7}$ Although we order this variable based on the degree of complexity as considered in Appendix A, it would make no difference to the results if we used separate dummy variables for $\mathrm{C}$ products and VC products.
} 
known at the end of the experiment by subjects. With this variable we control for possible income and risk aversion effects; as it is normally assumed that wealthier subjects are more risk loving, these effects would work in the direction of a positive coefficient (richer subjects should purchase more units of the product). Lagged Total Sales is the overall number of units bought up to the previous period. It shows whether subjects take into account the number of units they have bought in the previous periods to decide how much they want to buy this period. It helps to control for portfolio effects. In particular, it can be argued that a rational investor has an optimal portfolio to achieve over the 20 periods (in terms of safe and risky assets) but does not know how prices are determined. She initially assumes that prices are based on average as per the prices observed so far (as she has no better information). Given those prices, she aims to obtain a given number of units initially and at any given point of the experiment, and decides how many units to buy in each period based on her price expectation. When the prices increase in phase 2 of treatments 0 and 1 , she realises that now prices are much higher and, given her optimal portfolio of assets, the new prices and the amount of units she already holds, she will become the more reluctant to buy further units the more the units she has already bought. The reverse argument applies if subjects are in treatments 3 and 4 . If there are meaningful portfolio effects, we should therefore expect a negative coefficient on Lagged Total Sales, particularly as there is considerable variance in amounts of units bought from phase 1 across treatments (as shown by Figure 1). The MarketPeriod is the period of play, and shows how the number of units bought changes over time. T0, T1, T3 and T4 are 4 dummy variables that are equal to 1 when the treatment is respectively $0,1,3$ and 4 . Treatment 2 is the reference control treatment. When controlling for income and portfolio effects, and the other variables, the sign and statistical significance (if any) of these dummy variables in the phase 2 regressions help us test for shaping effects. The variable Complex*Price aims to test whether product complexity affects the elasticity of demand. Other interaction terms relate the period of play and the treatment dummy (e.g., MarketPeriod*T0). With these variables we are able to see whether behavior over time changes across treatments. Finally there are the interaction terms that relate the prices and 
treatments. These variables allow us to see whether subjects' sensitivity to prices changes across treatments. ${ }^{8}$

Consistently with the law of demand, current sales are negatively affected by the current price. Lower expenditure also results from a higher current price. The lagged price has a positive effect on sales: the higher the price in the previous period, the greater the sales and expenditure in the present period. As discussed earlier, this can be interpreted as period by period evidence for shaping effects and replicates Sitzia and Zizzo (2009). Neither the types of products used nor their different complexity level, at least as we have measured it, have a significant effect on sales or expenditure. There are wealth effects, but they work in the opposite direction than predicted, with richer subjects buying and spending less. The coefficients on LaggedTotalSales are statistically significant but positive, which is the opposite sign to the one that we would expect to find if portfolio effects were important.

When controlling for all these effects, as noted earlier, the treatment variables are especially useful to identify shaping effects. If there were no significant shaping effects, there should not be any differences between the treatments being the pricing strategy the same. The coefficients on T0, T1, T3 and T4 are all in the directions predicted by shaping effects, and the coefficients on T1 and T3 are both quantitatively large and statistically significant. Our benchmark treatment is the control treatment 2 where the pricing strategy does not change across phases. In treatments 0 and 4 prices partially adjust in the middle of phase 1 and then further, to a higher or lower value respectively, at the start of phase 2 . In treatments 1 and 3 prices have only a single adjustment, to a higher or lower value respectively, at the start of phase 2. When implemented as a single average price shift, the implementation of a 'high low' pricing strategy is clearly beneficial in raising sales and expenditure, whereas the reverse strategy damages them. Sales and expenditure generally increase with time. The reverse signs on the interaction terms of the treatment dummies with MarketPeriod - statistically significant in the case of

\footnotetext{
${ }^{8}$ We use centered price variables as different treatments are characterized by different average prices and this would be spuriously captured by these variables otherwise. Centering the price means to take the deviation from the average treatment price. For a discussion of the centering technique, see Marquardt (1980).
} 
MarketPeriod $^{\star} \mathrm{T} 1$ and MarketPeriod ${ }^{\star} \mathrm{T} 3$ - suggest that the shaping effect tends to partially decrease in size with time as subjects adjust to the new reference price. That being said, as late as in the last period of the experiment (period 20), in treatment 3 subjects still buy on average 0.8 units more than in the baseline treatment 2, and some 2 units more than in treatment 1 . A final result is that of an increasing price sensitivity of demand in treatments other than the baseline treatment 2 , all treatments characterized by large average price shifts as the subjects move into phase 2.

Result 4: The regression analysis supports the existence of treatment level and period by period shaping effects in sales and expenditures even controlling for a number of factors, such as price, product type, and income and portfolio effects. At the treatment level, increased sales and expenditure are observed in treatment 3 , while reduced sales and expenditure are observed in treatment 4.

\subsection{Profitability Analysis}

So far we have seen that the differences in the pricing strategies bring about shaping effects leading to significant differences in sales and expenditure in phase 2 . The question then becomes whether the increased sales and expenditure of the "high low' strategy of treatments 3 and 4 is successful in making such a strategy profitable for firms. Two considerations are relevant for determining this. First, we need to pool phase 1 and phase 2 as the firm may rationally decide to make a loss in phase 1 if this is more than compensated by gains in phase 2 : the key is the overall profitability of a given strategy rather than the profitability of part of it. Second, profits are equal to revenue minus costs. In our setup, revenue is the consumer expenditure, but we need to make assumptions about costs in order to be able to provide an answer on profits. Furthermore, the size of the market will also matter as it may affect the marginal cost of producing more units. We assume a simple and general cost function which allows us to model both different market sizes and different returns to scale:

(1) $\quad Y=x^{\alpha}$ 
where $Y$ is the cost and $x$ is the number of units produced, which in our case corresponds to the number of units sold. According to the value that we choose for $\alpha$, we can estimate the cost for decreasing $(\alpha<1)$, constant $(\alpha=1)$ and increasing $(\alpha>$ 1) returns to scale. The values that we used are $\alpha=0.5,0.75,1,1.25,1.5$ and 2 , and so cover all three cases. To estimate the costs, and assuming a market with a single consumer, we calculated the average number of units bought in each period for every treatment and then substituted this value into the cost function. From these estimated costs we then derived the profits for each period and treatment. In order to get cost and revenue estimates for different market sizes, we also multiplied the average number of units in each period by factors of 10,100,1,000,10,000,100,000 and 1,000,000. Table 6 describes the results of our profitability analysis: it shows the average estimated profits per treatment and cost function. The interesting values are the positive ones, as firms obviously would not choose to produce if they are making a loss. 
Table 6: Estimated Average Profits per Treatment, Market Size and $\alpha$

\begin{tabular}{|c|c|c|c|c|c|c|}
\hline \multirow[b]{2}{*}{$\alpha$} & \multicolumn{2}{|l|}{ Market } & \multicolumn{3}{|c|}{ Treatment } & \multirow[b]{2}{*}{4} \\
\hline & Size & 0 & 1 & 2 & 3 & \\
\hline \multirow[t]{7}{*}{0.5} & 1 & 203.17 & 187.47 & 188.29 & 223.40 & 201.30 \\
\hline & 10 & 203.40 & 187.67 & 188.48 & 223.59 & 201.49 \\
\hline & 100 & 203.48 & 187.73 & 188.53 & 223.65 & 201.54 \\
\hline & 1000 & 203.50 & 187.75 & 188.55 & 223.67 & 201.56 \\
\hline & 10000 & 203.51 & 187.76 & 188.56 & 223.68 & 201.57 \\
\hline & 100000 & 203.51 & 187.76 & 188.56 & 223.68 & 201.57 \\
\hline & 1000000 & 203.52 & 187.76 & 188.56 & 223.68 & 201.57 \\
\hline \multirow[t]{7}{*}{0.75} & 1 & 199.16 & 188.03 & 187.22 & 222.26 & 200.29 \\
\hline & 10 & 199.94 & 188.69 & 187.81 & 222.88 & 200.85 \\
\hline & 100 & 200.38 & 189.07 & 188.14 & 223.23 & 201.16 \\
\hline & 1000 & 200.62 & 189.28 & 188.32 & 223.43 & 201.34 \\
\hline & 10000 & 200.76 & 189.40 & 188.43 & 223.54 & 201.44 \\
\hline & 100000 & 200.84 & 189.47 & 188.49 & 223.60 & 201.50 \\
\hline & 1000000 & 200.88 & 189.50 & 188.52 & 223.64 & 201.53 \\
\hline \multirow[t]{7}{*}{1} & 1 & 201.19 & 186.00 & 187.08 & 222.07 & 200.16 \\
\hline & 10 & 201.19 & 186.00 & 187.08 & 222.07 & 200.16 \\
\hline & 100 & 201.19 & 186.00 & 187.08 & 222.07 & 200.16 \\
\hline & 1000 & 201.19 & 186.00 & 187.08 & 222.07 & 200.16 \\
\hline & 10000 & 201.19 & 186.00 & 187.08 & 222.07 & 200.16 \\
\hline & 100000 & 201.19 & 186.00 & 187.08 & 222.07 & 200.16 \\
\hline & 1000000 & 201.19 & 186.00 & 187.08 & 222.07 & 200.16 \\
\hline \multirow[t]{7}{*}{1.25} & 1 & 197.97 & 187.42 & 186.93 & 221.85 & 200.02 \\
\hline & 10 & 195.66 & 185.76 & 185.65 & 220.42 & 198.82 \\
\hline & 100 & 191.55 & 182.80 & 183.39 & 217.88 & 196.68 \\
\hline & 1000 & 184.25 & 177.55 & 179.36 & 213.37 & 192.88 \\
\hline & 10000 & 171.26 & 168.21 & 172.19 & 205.35 & 186.11 \\
\hline & 100000 & 148.16 & 151.61 & 159.46 & 191.08 & 174.08 \\
\hline & 1000000 & 107.09 & 122.07 & 136.80 & 165.70 & 152.68 \\
\hline \multirow[t]{7}{*}{1.5} & 1 & 188.03 & 176.96 & 180.49 & 214.52 & 194.12 \\
\hline & 10 & 154.55 & 153.61 & 163.04 & 194.71 & 178.02 \\
\hline & 100 & 48.68 & 79.76 & 107.84 & 132.07 & 127.09 \\
\hline & 1000 & -286.12 & -153.77 & -66.69 & -66.02 & -33.95 \\
\hline & 10000 & -1344.84 & -892.25 & -618.61 & -692.44 & -543.21 \\
\hline & 100000 & -4692.82 & -3227.55 & -2363.94 & -2673.34 & -2153.64 \\
\hline & 1000000 & -15280.05 & -10612.40 & -7883.16 & -8937.50 & -7246.26 \\
\hline \multirow[t]{7}{*}{2} & 1 & 203.42 & 187.69 & 188.43 & 223.60 & 201.52 \\
\hline & 10 & 193.22 & 181.13 & 184.17 & 218.48 & 197.62 \\
\hline & 100 & 100.54 & 121.40 & 144.61 & 171.65 & 162.09 \\
\hline & 1000 & -826.27 & -475.87 & -250.94 & -296.65 & -193.24 \\
\hline & 10000 & -10094.31 & -6448.52 & -4206.50 & -4979.62 & -3746.48 \\
\hline & 100000 & -102774.79 & -66175.06 & -43762.07 & -51809.31 & -39278.93 \\
\hline & 1000000 & -1029579.53 & -663440.47 & -439317.78 & -520106.22 & -394603.43 \\
\hline
\end{tabular}

Notes: $\alpha$ is the return to scale coefficient in equation 1; the market size is expressed as the number of consumers buying from the firm. 
We find that, for all our $\alpha$ and market size combinations yielding positive profits, profit values are greater for treatment 3 than for the other treatments; treatment 4 profits are also higher than in treatments 1,2 and, for $\alpha>0.5$, treatment 0 . For every profitable $\alpha$ and market size combinations, the prediction that profits are greater with a 'high low' strategy is always supported for the treatment 3 strategy (at $\mathrm{P}<0.05$ or better); ${ }^{9}$ the same prediction receives some, though less, support for treatment 4 , especially if $\alpha>1$ and with large market sizes. Table 7 contains the relevant Mann Whitney $\mathrm{P}$ values.

\footnotetext{
${ }^{9}$ The only exception is for $\alpha=0.75$ in the comparison of treatment 3 with treatment 1 , where $P=0.08$.
} 
Table 7: Mann-Whitney P Values of Prediction of Greater Profits with a 'High Low' Pricing Strategy

\begin{tabular}{|c|c|c|c|c|c|c|c|c|}
\hline \multirow{2}{*}{$\begin{array}{c}\text { Treatments } \\
\text { Comparisons }\end{array}$} & \multicolumn{6}{|c|}{ Market Size (number of consumers) } & \multirow[b]{2}{*}{100000} & \multirow[b]{2}{*}{1000000} \\
\hline & $\alpha$ & 1 & 10 & 100 & 1000 & 10000 & & \\
\hline \multirow[t]{6}{*}{ Treatment 0 - Treatment 2} & 0.5 & 0.21 & 0.21 & 0.21 & 0.21 & 0.21 & 0.21 & 0.21 \\
\hline & 0.75 & 0.14 & 0.14 & 0.15 & 0.15 & 0.15 & 0.15 & 0.15 \\
\hline & 1 & 0.19 & 0.19 & 0.19 & 0.19 & 0.19 & 0.19 & 0.19 \\
\hline & 1.25 & 0.13 & 0.13 & 0.12 & 0.10 & 0.08 & 0.05 & 0.00 \\
\hline & 1.5 & 0.11 & 0.02 & 0.00 & & & & \\
\hline & 2 & 0.20 & 0.11 & 0.00 & & & & \\
\hline \multirow[t]{6}{*}{ Treatment 0 - Treatment 3} & 0.5 & 0.03 & 0.03 & 0.03 & 0.03 & 0.03 & 0.03 & 0.03 \\
\hline & 0.75 & 0.02 & 0.02 & 0.02 & 0.02 & 0.02 & 0.02 & 0.02 \\
\hline & 1 & 0.02 & 0.02 & 0.02 & 0.02 & 0.02 & 0.02 & 0.02 \\
\hline & 1.25 & 0.01 & 0.01 & 0.01 & 0.01 & 0.00 & 0.00 & 0.00 \\
\hline & 1.5 & 0.02 & 0.00 & 0.00 & & & & \\
\hline & 2 & 0.03 & 0.02 & 0.00 & & & & \\
\hline \multirow[t]{6}{*}{ Treatment 0 - Treatment 4} & 0.5 & 0.15 & 0.15 & 0.15 & 0.15 & 0.15 & 0.15 & 0.15 \\
\hline & 0.75 & 0.10 & 0.10 & 0.10 & 0.10 & 0.10 & 0.10 & 0.10 \\
\hline & 1 & 0.14 & 0.14 & 0.14 & 0.14 & 0.14 & 0.14 & 0.14 \\
\hline & 1.25 & 0.10 & 0.10 & 0.09 & 0.07 & 0.04 & 0.01 & 0.00 \\
\hline & 1.5 & 0.07 & 0.02 & 0.00 & & & & \\
\hline & 2 & 0.15 & 0.09 & 0.00 & & & & \\
\hline \multirow{6}{*}{ Treatment 1 - Treatment 2} & 0.5 & 0.45 & 0.45 & 0.45 & 0.45 & 0.45 & 0.45 & 0.45 \\
\hline & 0.75 & 0.45 & 0.45 & 0.45 & 0.45 & 0.45 & 0.45 & 0.45 \\
\hline & 1 & 0.45 & 0.45 & 0.45 & 0.45 & 0.45 & 0.45 & 0.45 \\
\hline & 1.25 & 0.45 & 0.45 & 0.45 & 0.45 & 0.45 & 0.45 & 0.19 \\
\hline & 1.5 & 0.42 & 0.37 & 0.00 & & & & \\
\hline & 2 & 0.44 & 0.42 & 0.09 & & & & \\
\hline \multirow[t]{6}{*}{ Treatment 1 - Treatment 3} & 0.5 & 0.05 & 0.05 & 0.05 & 0.05 & 0.05 & 0.05 & 0.05 \\
\hline & 0.75 & 0.07 & 0.08 & 0.08 & 0.08 & 0.08 & 0.08 & 0.08 \\
\hline & 1 & 0.05 & 0.05 & 0.05 & 0.05 & 0.05 & 0.05 & 0.05 \\
\hline & 1.25 & 0.07 & 0.07 & 0.06 & 0.05 & 0.03 & 0.00 & 0.00 \\
\hline & 1.5 & 0.05 & 0.02 & 0.00 & & & & \\
\hline & 2 & 0.05 & 0.05 & 0.01 & & & & \\
\hline \multirow[t]{6}{*}{ Treatment 1 - Treatment 4} & 0.5 & 0.31 & 0.31 & 0.31 & 0.31 & 0.31 & 0.31 & 0.31 \\
\hline & 0.75 & 0.39 & 0.39 & 0.39 & 0.39 & 0.39 & 0.39 & 0.39 \\
\hline & 1 & 0.31 & 0.31 & 0.31 & 0.31 & 0.31 & 0.31 & 0.31 \\
\hline & 1.25 & 0.38 & 0.37 & 0.37 & 0.34 & 0.29 & 0.12 & 0.00 \\
\hline & 1.5 & 0.27 & 0.12 & 0.00 & & & & \\
\hline & 2 & 0.31 & 0.27 & 0.02 & & & & \\
\hline \multirow[t]{6}{*}{ Treatment 2 - Treatment 3} & 0.5 & 0.00 & 0.00 & 0.00 & 0.00 & 0.00 & 0.00 & 0.00 \\
\hline & 0.75 & 0.00 & 0.00 & 0.00 & 0.00 & 0.00 & 0.00 & 0.00 \\
\hline & 1 & 0.00 & 0.00 & 0.00 & 0.00 & 0.00 & 0.00 & 0.00 \\
\hline & 1.25 & 0.00 & 0.00 & 0.00 & 0.00 & 0.00 & 0.00 & 0.00 \\
\hline & 1.5 & 0.00 & 0.00 & 0.04 & & & & \\
\hline & 2 & 0.00 & 0.00 & 0.03 & & & & \\
\hline \multirow[t]{6}{*}{ Treatment 2 - Treatment 4} & 0.5 & 0.02 & 0.02 & 0.02 & 0.02 & 0.02 & 0.02 & 0.02 \\
\hline & 0.75 & 0.02 & 0.02 & 0.02 & 0.02 & 0.02 & 0.02 & 0.02 \\
\hline & 1 & 0.02 & 0.02 & 0.02 & 0.02 & 0.02 & 0.02 & 0.02 \\
\hline & 1.25 & 0.02 & 0.02 & 0.02 & 0.01 & 0.01 & 0.00 & 0.00 \\
\hline & 1.5 & 0.02 & 0.02 & 0.03 & & & & \\
\hline & 2 & 0.02 & 0.02 & 0.06 & & & & \\
\hline
\end{tabular}


Notes: the table contains the $P$ values of the relevant pairwise Mann Whitney tests. $\alpha$ is the return to scale coefficient in equation 1.

Result 5: A pricing strategy of pricing high and then decreasing prices, especially as implemented in treatment 3 , is more profitable than a constant pricing strategy or a 'low high' strategy.

\section{Conclusions}

Our experiment showed that starting with a high price and then decreasing it can be profitable for firms. Reasons, consistent with rational choice, have been identified in the literature for why a 'high low' strategy may be profitable, in the form, most notably, of price discrimination with durable goods (Conlisk et al., 1984) and of a game theoretical setup quality signalling (Bagwell and Riordan, 1991). Our experimental results suggest that, independently of such reasons, although in the spirit of quality signalling, a strong reason why a 'high low' pricing strategy may be a good one lies in shaping effects: subjects may not have clear preferences about the value of a product and rely on past prices to provide an indication of what such value is. Firms, in turn, may then exploit consumers' bounded rationality to gain more profits than they would otherwise. A number of extensions to this research are possible, for example trying to get a better understanding of what price dynamics yields the highest profits or verifying how the profit-maximising price dynamics is affected by the presence of multiple products simultaneously on sale.

\section{Appendix A: Deriving the products}

The procedure employed in Sitzia and Zizzo (2009), and used to derive a complex lottery (product) for each simple product (S1, S2 and S3), is based on deriving compound lotteries (products) from simple lotteries (products) using small payoff perturbations in a sense detailed below, and on presenting the resulting compound products using a scrambled order format. The procedure enables large changes in product complexity - due to the additional outcomes (27 rather than 3) combined with order scrambling - while making the riskiness of the products indistinguishable, and therefore controlling as much as possible for differences in 
preferences between products for reasons other than complexity. Define $p_{i}>0$ and $\sum p_{i}=1$ as the probabilities attached to outcomes $x_{i}$. The simple lotteries, or products, $L_{s j}$ have three possible outcomes and associated probabilities:

$$
L_{s j}=\left(p_{1}, x_{1} ; p_{2}, x_{2} ; p_{3}, x_{3}\right)
$$

Complex products can then be generated by deriving, for any given $L_{s j}$, a compound lottery $L_{c j}$ that assigns weights $\alpha, \beta$ and $(1-\alpha-\beta)$ to the outcomes of 3 draws of $L_{s j}$. That is,

$$
L_{c j}: L_{c j}=\alpha L_{s j}+\beta L_{s j}+(1-\alpha-\beta) L_{s j}
$$

which is to say that each complex product $L_{c j}$ can be obtained by making three draws of $L_{s j}$, assigning weights $\alpha, \beta$ and $(1-\alpha-\beta)$ to the outcomes of each draw, and summing up the three weighted payoffs to obtain the $L_{c j}$ payoffs structure. To make a simple example, if $L_{s j}$ were just a flip of a coin with 50 per cent chance of getting 12 pounds $\left(x_{1}\right)$ and 50 per cent of getting $0\left(x_{2} .+x_{3}\right)$, and if $\alpha=\beta=1 / 3$, then $L_{c j}$ would correspond to the compound lottery obtained by flipping the coin three times with a 50 per cent chance of getting 4 pounds each time.

Generally speaking, $L_{c j}$ has $3 \times 3 \times 3=27$ possible outcomes, and, although in principle some outcomes may yield the same payoff and so may not be separable, the simple products we chose were such that this did not occur in practice, and so there were 27 differentiated outcomes in the complex product (as opposed to the 3 of simple products). While the procedure might in principle mean that $L_{c j}$ is perceived as having a different degree of riskiness relative to $L_{s j}$, this potential problem can be reduced (a) by choosing $\alpha$ and $\beta$ small enough as to imply just a small payoff perturbation while still multiplying the number of outcomes. In our experiment, we chose $\alpha=0.03$ and $\beta=0.07$, and so our products were defined as $L_{c j}=0.03 L_{s j}+$ $0.07 L_{s j}+0.9 L_{s j}$, and, (b) as in Sonsino et al. (2002), by scrambling the order of presentation of the 27 outcomes (see Table 2), ${ }^{10}$ thus further helping make the products undistinguishable to the buyers in terms of risk while at the same time being markedly different in terms of complexity. ${ }^{11}$

\footnotetext{
${ }^{10}$ That is, outcomes were not presented from lowest to highest (or vice versa) but instead in a random order.

${ }^{11}$ This is confirmed by the fact that we did not receive any debriefing feedback suggesting that subjects perceived products different in terms of risk. A by-product of our procedure, also entailing additional complexity, was that,
} 
Alternatively, and for comparability, we employed the mixing procedure used in Sonsino et al. (2002), setting $\alpha=0.5$ and $\beta=0$ in equation, thus $L_{c j}=0.5 L_{s j}+0.5 L_{s j}$, which leads to products which are less complex than those derived in Sitzia and Zizzo (2009) and which have a marked difference in riskiness rather than just complexity. We label the products derived from S1, S2 and S3 using the Sonsino et al.'s procedure as complex products $\mathrm{C} 1, \mathrm{C} 2$ and $\mathrm{C} 3$ respectively; we label the products derived from S1, S2 and S3 using the Sonsino et al.'s procedure as very complex products VC1, VC2 and VC3 respectively.

All the products are reproduced in Table 1 in the main text.

\section{Appendix B: Alternative Regression Specifications}

Table 8 contains the results of OLS and ordered probit regressions on phase 2 sales and expenditure, both with error clustering as the method employed to correct for the non independence of repeated observations by the same subject.

Table 8: Alternative Regression Specifications

(a) OLS Regressions with error clustering 


\begin{tabular}{|c|c|c|c|c|c|c|}
\hline \multirow[b]{2}{*}{ Variables } & \multicolumn{3}{|c|}{ Regression on Sales } & \multicolumn{3}{|c|}{ Regression on Expenditure } \\
\hline & $\beta$ & S.E. & $P$ & $\beta$ & S.E. & $P$ \\
\hline Price & -0.057 & 0.012 & 0.000 & -5.949 & 1.517 & 0.000 \\
\hline Lagged Price & 0.009 & 0.002 & 0.000 & 1.089 & 0.246 & 0.000 \\
\hline Lotteries 1 & 0.002 & 0.076 & 0.976 & 0.345 & 9.601 & 0.971 \\
\hline Lotteries 2 & 0.048 & 0.081 & 0.557 & 6.111 & 10.265 & 0.552 \\
\hline Complexity & 0.474 & 0.660 & 0.474 & 50.532 & 80.713 & 0.532 \\
\hline Complexity*Price & -0.004 & 0.005 & 0.449 & -0.415 & 0.627 & 0.509 \\
\hline Lagged Income & -0.0009 & 0.000 & 0.000 & -0.114 & 0.012 & 0.000 \\
\hline Lagged Total Sales & 0.042 & 0.003 & 0.000 & 5.296 & 0.347 & 0.000 \\
\hline MarketPeriod & 0.510 & 0.064 & 0.000 & 64.503 & 8.159 & 0.000 \\
\hline T0 & -0.176 & 0.453 & 0.698 & -15.690 & 57.042 & 0.783 \\
\hline $\mathrm{T} 1$ & -0.868 & 0.336 & 0.010 & -105.705 & 42.422 & 0.013 \\
\hline $\mathrm{T} 3$ & 1.095 & 0.363 & 0.003 & 143.353 & 45.748 & 0.002 \\
\hline $\mathrm{T} 4$ & 0.109 & 0.587 & 0.853 & 21.037 & 73.978 & 0.776 \\
\hline MarketPeriod ${ }^{*} \mathrm{~T} 0$ & 0.025 & 0.025 & 0.313 & 2.910 & 3.162 & 0.358 \\
\hline MarketPeriod*T1 & 0.045 & 0.021 & 0.037 & 5.476 & 2.690 & 0.042 \\
\hline MarketPeriod*T3 & -0.061 & 0.023 & 0.008 & -7.949 & 2.892 & 0.006 \\
\hline MarketPeriod*T4 & -0.013 & 0.037 & 0.732 & -1.989 & 4.604 & 0.666 \\
\hline cPrice*T0 & 0.031 & 0.012 & 0.008 & 3.740 & 1.452 & 0.010 \\
\hline cPrice*T1 & 0.042 & 0.009 & 0.000 & 4.902 & 1.168 & 0.000 \\
\hline cPrice*T3 & 0.008 & 0.011 & 0.470 & 1.464 & 1.326 & 0.270 \\
\hline cPrice*T4 & 0.013 & 0.015 & 0.376 & 2.052 & 1.837 & 0.265 \\
\hline Constant & 7.016 & 1.653 & 0.000 & 717.727 & 200.054 & 0.000 \\
\hline
\end{tabular}

(b) Ordered Probit Regressions with error clustering 


\begin{tabular}{|c|c|c|c|c|c|c|}
\hline \multirow[b]{2}{*}{ Variables } & \multicolumn{3}{|c|}{ Regression on Sales } & \multicolumn{3}{|c|}{ Regression on Expenditure } \\
\hline & $\beta$ & S.E. & $P$ & $\beta$ & S.E. & $P$ \\
\hline Price & -0.069 & 0.013 & 0.000 & -0.042 & 0.013 & 0.001 \\
\hline Lagged Price & 0.009 & 0.002 & 0.000 & 0.009 & 0.002 & 0.000 \\
\hline Lotteries 1 & 0.034 & 0.074 & 0.645 & 0.029 & 0.072 & 0.684 \\
\hline Lotteries2 & -0.017 & 0.079 & 0.833 & -0.025 & 0.077 & 0.741 \\
\hline Complexity & 0.108 & 0.672 & 0.873 & -0.013 & 0.645 & 0.984 \\
\hline Complexity*Price & -0.001 & 0.005 & 0.856 & 0.000 & 0.005 & 0.998 \\
\hline Lagged Income & -0.001 & 0.000 & 0.000 & -0.001 & 0.000 & 0.000 \\
\hline Lagged Total Sales & 0.040 & 0.003 & 0.000 & 0.039 & 0.003 & 0.000 \\
\hline MarketPeriod & 0.425 & 0.066 & 0.000 & 0.383 & 0.063 & 0.000 \\
\hline T0 & -0.147 & 0.469 & 0.754 & -0.116 & 0.464 & 0.802 \\
\hline $\mathrm{T} 1$ & -1.003 & 0.360 & 0.005 & -0.945 & 0.354 & 0.008 \\
\hline $\mathrm{T} 3$ & 0.950 & 0.334 & 0.004 & 0.989 & 0.324 & 0.002 \\
\hline $\mathrm{T} 4$ & -0.006 & 0.554 & 0.991 & 0.146 & 0.541 & 0.787 \\
\hline MarketPeriod*T0 & 0.017 & 0.026 & 0.510 & 0.012 & 0.026 & 0.651 \\
\hline MarketPeriod ${ }^{*} \mathrm{~T} 1$ & 0.051 & 0.022 & 0.022 & 0.046 & 0.022 & 0.034 \\
\hline MarketPeriod*T3 & -0.053 & 0.021 & 0.013 & -0.054 & 0.021 & 0.009 \\
\hline MarketPeriod*T4 & -0.007 & 0.035 & 0.843 & -0.015 & 0.033 & 0.647 \\
\hline cPrice*T0 & 0.037 & 0.012 & 0.002 & 0.031 & 0.012 & 0.010 \\
\hline cPrice*T1 & 0.044 & 0.010 & 0.000 & 0.036 & 0.010 & 0.000 \\
\hline cPrice*T3 & 0.012 & 0.011 & 0.242 & 0.016 & 0.010 & 0.105 \\
\hline cPrice*T4 & 0.010 & 0.016 & 0.528 & 0.017 & 0.015 & 0.262 \\
\hline
\end{tabular}

Notes: the regressions are on phase 2 sales and expenditure and control for subject level effects $(n=3840)$. 


\section{References}

Ariely, D., 2008. The irrationalities of product pricing. Wall Street Journal Eastern Edition 252, R2-R2.

Ariely, D., Loewenstein, G., Prelec, D., 2003. "Coherent arbitrariness": Stable demand Curves without stable preferences. Quarterly Journal of Economics 118, 73-105.

Ariely, D., Loewenstein, G., Prelec, D., 2006. Tom Sawyer and the construction of value. Journal of Economic Behavior and Organization 60, 1-10.

Bagwell, K., 1987. Introductory price as a signal of cost in a model of repeat business. Review of Economic Studies 54, 365-384.

Bagwell, K., Riordan, M. H., 1991. High and declining prices signal product quality. American Economic Review 81, 224-239.

Bass, F. M., 1980. The relationship between diffusion rates, experience curves, and demand elasticities for consumer durable technological innovations. Journal of Business 53, S51-S67.

Bateman, I., Munro, A., Rhodes, B., Starmer, C., Sugden, R., 1997. A test of the theory of reference-dependent preferences. Quarterly Journal of Economics 112, 479-505.

Braga, J., Humphrey, S. J., Starmer, C., 2009. Market experience eliminates some anomalies--and creates new ones. European Economic Review 53, 401-416.

Brooks, P., Isoni, A., Loomes, G., Sugden, R., 2008. Monetary valuations in repeated markets: Do prices matter? University of East Anglia Working Paper.

Cabral, L. M. B., 2010. Lock in and switch: Asymmetric information and new product diffusion. Journal of Industrial Organization Forthcoming.

Camelot Group plc., 2009. Camelot Stakeholder Report 2008-09. W. C. G. plc.

Conlisk, J., Gerstner, E., Sobel, J., 1984. Cyclic pricing by a durable goods monopolist. Quarterly Journal of Economics 99, 489-505.

Consumer Report., 2008. Appliance Stores. Consumer Reports 73, 44-46.

Fitzgerald, K., 1992. Toy marketers bank on "gross" sales. Advertising Age 63, 1414. 
Heidhues, P., Köszegi, B., 2008. competition and price variation when consumers are loss averse. 98, 1245-1268.

Hilty, J. A., Carnevale, P. J., 1993. Black-hat/white-hat strategy in bilateral negotiation. Organizational Behavior and Human Decision Processes 55, 444469.

Isoni, A., 2009. Price sensitivity, "bad-deal" aversion, and the wta/wtp disparity. CSERGE Working Paper EDM 09-06.

Kahneman, D., Tversky, A., 1979. Prospect theory: An analysis of decision under risk. Econometrica 47, 263-291.

Klemperer, P., 1995. Competition when consumers have switching costs: An overview with applications to industrial organization, macroeconomics, and international trade. Review of Economic Studies 62, 515-539.

Köszegi, B., Rabin, M., 2006. A model of reference-dependent preferences. Quarterly Journal of Economics 121, 1133-1165.

Krishnan, T. V., Bass, F. M., Jain, D. C., 1999. Optimal pricing strategy for new products. Management Science 45, 1650-1663.

Loomes, G., Starmer, C., Sugden, R., 2003. Do anomalies disappear in repeated markets? Economic Journal 113, C153-C166.

Lucke, T., Hogan, J., 2007. The price of anything is the forgone alternative. USA Today $135,62-64$.

Marquard, D. W., 1980. you should standardize the predictor variables in your regression models. Journal of the American Statistical Association 75, 87-91.

Morris, M. H., Gene, M. P., 1990. Market-Oriented Pricing. Westport, CT: Quorum Books.

Munro, A., Sugden, R., 2003. On the theory of reference-dependent preferences. Journal of Economic Behavior and Organization 50, 407-428.

Schlee, E. E., 2001. Buyer experimentation and introductory pricing. Journal of Economic Behavior and Organization 44, 347-362.

Sitzia, S., Zizzo, D., 2009. Does product complexity matter for competition in experimental retail markets? Theory and Decision, forthcoming. 
Sonsino, D., Benzion, U., Mador, G., 2002. The complexity effects on choice with uncertainty - experimental evidence. Economic Journal 112, 936-965.

Tufano, F. Are 'true' preferences revealed in repeated markets? An experimental demonstration of context-dependent valuations. Experimental Economics 13, 113. 